\title{
Identification of glycosomes and metabolic end products in pathogenic and nonpathogenic strains of Cryptobia salmositica (Kinetoplastida: Bodonidae)
}

\author{
B. F. Ardelli, J. D. S. Witt, P. T. K. Woo* \\ Department of Zoology, University of Guelph, Guelph, Ontario N1G 2W1, Canada
}

\begin{abstract}
Whole cell lysates of pathogenic and nonpathogenic strains of Cryptobia salmositica were subjected to subcellular fractionation using differential and isopycnic centrifugation in sucrose. The glycolytic enzymes hexokinase, fructose-1,6-biphosphate aldolase, triosephosphate isomerase, glucosephosphate isomerase and glyceraldehyde-3-phosphate-dehydrogenase and the peroxisomal enzyme catalase were associated with a microbody that had a buoyant density in sucrose of $1.21 \mathrm{~g}$ $\mathrm{cm}^{-3}$. Lactate dehydrogenase was detected in whole cell lysates, but not in purified organelles. A microbody with a positive reaction for catalase was detected in electron microscope sections of the pathogenic and nonpathogenic strains. These catalase-containing microbodies fused with lipid bodies and vacuoles, arose by division from pre-existing microbodies and expelled their contents into the cytoplasm of the cell. Both strains also modified the catalase content in their microbodies. Under aerobic conditions, they metabolized glucose to pyruvate and lactate. We conclude that part of the glycolytic pathway in C. salmositica is compartmentalized in a microbody called the glycosome.
\end{abstract}

KEY WORDS: Cryptobia $\cdot$ Glycosome $\cdot$ Glycolytic enzymes $\cdot$ Catalase $\cdot$ Pyruvate $\cdot$ Lactate

Resale or republication not permitted without written consent of the publisher

\section{INTRODUCTION}

Cryptobia salmositica is a haemoflagellate which infects Oncorhynchus spp. on the west coast of North America (Woo \& Poynton 1995) and is considered a lethal pathogen in semi-natural and intensive salmon culture facilities (Bower \& Margolis 1984). The parasite is transmitted indirectly by the bite of blood sucking aquatic leeches in freshwater streams and marine estuaries (Becker \& Katz 1965) or directly between fishes under laboratory and hatchery conditions (Woo \& Wehnert 1983). The pathogenic C. salmositica was attenuated by continuous in vitro culture (Woo\& Li 1990); the resulting strain is infective but does not cause disease in fish (Li \& Woo 1995). This attenuated strain of $C$. salmositica has been used successfully as a live vaccine (Ardelli et al. 1994, Sitja-Bobadilla \& Woo 1994,

*Corresponding author. E-mail: pwoo@uoguelph.ca
Li \& Woo 1995) and in comparative studies aimed at a better understanding of the disease mechanism (Zuo \& Woo 1996, 1997). Although C. salmositica causes morbidity and mortality in the economically important Oncorhynchus spp. and results in considerable loss in some west coast hatcheries, we know little of the biology of this pathogen.

Cryptobia salmositica consumes oxygen (Thomas et al. 1992) and utilizes glucose and L-glutamine under in vitro conditions ( $\mathrm{Li} \&$ Woo 1991). Prolonged exposure to sodium azide, a potent inhibitor of oxidative phosphorylation, reduces oxygen consumption and activity, but does not kill the parasite (Thomas et al. 1992). The recovery after removal of sodium azide is highly unusual because the latter normally kills aerobic organisms within minutes of exposure. Since both C. salmositica strains (pathogenic and nonpathogenic) consume oxygen and glucose under in vitro conditions, they likely utilize the Embden-Meyerhof pathway for the production of ATP. However Thomas et al. (1992) 
were unable to detect 3 key enzymes of carbohydrate and oxidative metabolism, namely hexokinase and pyruvate kinase of glycolysis and cytochrome $c$ oxidase of oxidative phosphorylation.

Members of the Kinetoplastida have an unusual organelle, the glycosome. It is bounded by a single membrane and contains 7 glycolytic enzymes, from hexokinase to phosphoglycerate kinase, which in other cells are cytoplasmic (Opperdoes \& Borst 1977). The Kinetoplastida are the only known living organisms where glycolysis is compartmentalized. The glycosomes may also contain enzymes of peroxide metabolism (Opperdoes 1988). It is assumed that the compartmentalization of glycolysis may facilitate the extremely high rate of glycolysis in the Kinetoplastida, particularly in bloodforms of Trypanosoma brucei (Opperdoes 1995).

We hypothesize that Cryptobia salmositica survives prolonged exposure to sodium azide because it is able to switch between aerobic respiration and anaerobic glycolysis. This switch may be accomplished, in part, because glycolysis is compartmentalized. To gain a better understanding of carbohydrate and energy metabolism in C. salmositica, the objectives of the present study were to (1) identify glycosomes and (2) determine some of the end products of glucose metabolism.

\section{MATERIALS AND METHODS}

In vitro culture of Cryptobia salmositica. A cloned strain of pathogenic C. salmositica was used to infect rainbow trout Oncorhynchus mykiss held at $11^{\circ} \mathrm{C}$. The strain was initially isolated from Piscicola salmositica and details of the cloning of the parasite and fish maintenance have been described earlier (Woo 1979). Blood from an infected trout was aseptically inoculated into sterile culture flasks containing Minimum Essential Medium (MEM) supplemented with Hanks's salts, L-glutamine, $25 \mathrm{mM}$ Hepes buffer, and $25 \%$ heat-inactivated foetal bovine serum, and cultured. Short-term culture of the pathogenic strain does not affect the pathogenicity (Woo \& Thomas 1992). The nonpathogenic vaccine strain of $C$. salmositica was cloned and has been maintained in MEM since 1989 (Woo \& Li 1990). This nonpathogenic strain was reinoculated into laboratory-raised chinook salmon Oncorhynchus tshawytscha and serially passaged monthly for 8 mo (G. Staines pers. comm.). It was also reisolated and maintained in MEM (present study).

Isolation and purification of microbodies (Opperdoes et al. 1984). Microbodies were isolated using a combination of differential and isopycnic centrifugation. Briefly, parasites were harvested by centrifuga- tion $(10700 \times g$ for $10 \mathrm{~min})$ and washed 5 times in cold tris-EDTA buffer ( $\mathrm{pH}$ 7.8) containing $0.25 \mathrm{M}$ sucrose, $25 \mathrm{mM}$ Tris- $\mathrm{HCl}$ and $1 \mathrm{mM}$ EDTA. Cells were disrupted by incubation $\left(1 \mathrm{~h}\right.$ at $\left.4{ }^{\circ} \mathrm{C}\right)$ in a $0.03 \%$ solution of Triton-X 100 and then disrupted cells were suspended in $25 \mathrm{ml}$ of Tris-EDTA buffer. This suspension was centrifuged at $1310 \times g$ for $10 \mathrm{~min}$ and the sediment removed. The supernatant was centrifuged at $4530 \times g$ for $10 \mathrm{~min}$, the sediment removed and the supernatant further centrifuged at $42900 \times g$ for $20 \mathrm{~min}$. The pellet was resuspended in $60 \mathrm{ml}$ of Tris-EDTA buffer and $10 \mathrm{ml}$ aliquots were layered on $10-60 \%$ (w/w) linear sucrose gradients dissolved in $25 \mathrm{mM}$ of Tris- $\mathrm{HCl}$ ( $\mathrm{pH} 7.2$ ) and $1 \mathrm{mM}$ of EDTA. A series of sucrose standards containing various concentrations of sucrose in Tris-EDTA buffer were prepared and the refractive indices (at $589 \mathrm{~nm}$ ) were measured at $20^{\circ} \mathrm{C}$ (Price 1982). The corresponding density was determined by comparing the refractive index of standards with values computed by Eikenberry (see Price 1982).

Gradients were centrifuged (60000 $\times g$ for $90 \mathrm{~min})$ in an ultracentrifuge equipped with a swinging-bucket rotor. After centrifugation, each sucrose gradient was removed by puncturing the tube and extracting the contents with a syringe. Next, gradients were centrifuged to pellet the contents, and pellets were prepared for transmission electron microscopy (see below) to determine the separation of cell organelles within each gradient. Microbodies were determined by a catalase-positive reaction (see below). The gradient containing catalase-positive organelles was further purified by passaging twice through sucrose gradients. The purified organelles were ruptured and prepared for electrophoresis to determine enzyme profiles.

Isozyme electrophoresis. Thomas et al. (1992) could not detect the enzymatic activity of hexokinase and pyruvate kinase. The same experiment was repeated in the present study and similar results were obtained. Studies of another pathogen (Opperdoes et al. 1988) indicate the glycolytic enzymes of Cryptobia spp. have low activity. As a result, electrophoresis was used in the present study to detect specific enzymes. This technique is sensitive and requires only small aliquots of the sample. Purified organelles (see above) were homogenized in Tris-EDTA buffer and centrifuged at $4^{\circ} \mathrm{C}$ to sediment organelle membranes. The supernatant was applied to cellulose acetate gels. Samples were electrophoresed in a Tris-glycine buffer $(\mathrm{pH}$ 8.5) at $200 \mathrm{~V}$ for $15 \mathrm{~min}$ and stained for glyceraldehydephosphate dehydrogenase (EC 1.2.1.12), glucosephosphate isomerase (EC 5.3.1.9), hexokinase (EC 2.7.1.1) and lactate dehydrogenase (EC 1.1.1.27) as described by Hebert \& Beaton (1993), and catalase (EC 1.11.1.6), fructose-1,6-biphosphate aldolase (EC 4.1.2.13) and triosephosphate isomerase (EC 5.3.1.1) as described by 
Harris \& Hopkinson (1976). Catalase activity was detected using $12.5 \%$ starch gels (Shaw \& Prasad 1970).

Preparation and fixation for transmission electron microscopy. To isolate parasites from the blood of fish, 10 to 15 drops of heat-inactivated horse serum were added to a heparinized blood sample $(1.0 \mathrm{ml})$ to agglutinate the red blood cells. The sample was centrifuged at $100 \times g$ for 5 min to sediment most of the agglutinated cells with the parasites still in the supernatant. Parasites from cultures were concentrated by centrifugation in a cold $\left(4^{\circ} \mathrm{C}\right)$ centrifuge at $6860 \times g$ for $15 \mathrm{~min}$.

Harvested parasites were washed 3 times by centrifugation $(15 \mathrm{~min}$ at $10700 \times g)$ in cold blooded vertebrate Ringer's solution and quantified using a haemocytometer (Archer 1965). Parasites $\left(1.0 \times 10^{6}\right)$ were fixed in $2.5 \%$ glutaraldehyde in $0.1 \mathrm{M}$ sodium cacodylate buffer $(\mathrm{pH} 7.2)$ at $4^{\circ} \mathrm{C}$ for 60 min, pelleted by centrifugation and washed 4 times in $0.1 \mathrm{M}$ sodium cacodylate buffer. Postfixation, dehydration and embedding were performed as described by Ardelli \& Woo (1998).

Sections of the pellet corresponding to a gold interference colour were cut using a Reichert microtome and diamond knife. Ribbons of 10 pellet sections were collected from the water surface on cleaned, uncoated copper-mesh grids and allowed to dry for $60 \mathrm{~min}$. Sections attached to grids were stained using saturated $(7.7 \%)$ uranyl acetate and acetone for $5 \mathrm{~min}$ and lead citrate for $1 \mathrm{~min}$. Pellet sections were examined using a JEOL 100CX electron microscope operating at $80 \mathrm{kV}$.

Detection of catalase. Cytochemistry: Glutaraldehyde-fixed parasites $\left(1.0 \times 10^{6}\right)$ were washed 4 times in $0.1 \mathrm{M}$ sodium cacodylate and incubated for $60 \mathrm{~min}$ at $37^{\circ} \mathrm{C}$ in $1 \mathrm{ml}$ of medium containing $0.7 \mathrm{mg} \mathrm{ml}^{-1}$ of diaminobenzidine tetrahydrochloride, $1.6 \mathrm{mg} \mathrm{ml}^{-1}$ of urea hydrogen peroxide and 0.6 M Tris buffer ( $\mathrm{pH}$ 7.8). Controls were incubated in $1 \mathrm{ml}$ of $50 \mathrm{mM} \mathrm{3-amino-}$ 1,2,4-triazole as inhibitor of catalase activity (SanchezMoreno et al. 1992).

Enzymatic analysis: Cryptobia salmositica $\left(1.0 \times 10^{6}\right)$ were washed 3 times by centrifugation (15 min at $10600 \times g$ ) in PBS. The pellet was resuspended in $0.2 \mathrm{ml}$ of phosphate buffer $\left(50 \mathrm{mM} \mathrm{l}^{-1}\right)$ and sonicated for $60 \mathrm{~s}$. The homogenate was used as the source of catalase activity. The protein concentration of the homogenate was determined according to Bradford (1976) and adjusted such that $0.2 \mathrm{ml}$ of sample contained $200 \mathrm{mg}$ of protein. Catalase (hydrogen-peroxide: hydrogen-peroxide oxidoreductase: EC 1.11.1.6) activity was assayed using the method of Lück (1963) and was expressed as units (mg protein) ${ }^{-1}$.

Quantification of glycosomes. Parasites fixed for transmission electron microscopy and stained for catalase were embedded in Spurr's resin to a depth of $3 \mathrm{~mm}$, and polymerized for $24 \mathrm{~h}$ at $60^{\circ} \mathrm{C}$. The first
30 pellet sections corresponding to a gold interference colour were discarded from each sample; the next 5 sections were collected on uncoated, copper-mesh grids. This was done for both pathogenic and nonpathogenic strains of Cryptobia salmositica such that 5 grids contained 5 pellet sections. Sections attached to grids were stained as described and examined using a JEOL 100CX electron microscope at $80 \mathrm{kV}$. Microbodies were quantified by counting 10 parasite sections, in each of the 5 pellet sections, for a total of 250 parasite sections.

Measurement of end products of carbohydrate metabolism. Thirty tissue culture flasks were divided into 3 groups (A, B, and $C_{i} n=10$ group $^{-1}$ ). Each flask contained $50 \mathrm{ml}$ of MEM (without phenol red) and was supplemented with $25 \%$ FBS, L-glutamine and $25 \mathrm{mM}$ Hepes. Each flask in Group B was inoculated with 100000 pathogenic Cryptobia salmositica and each in Group C with 100000 nonpathogenic C. salmositica. Control flasks (Group A) did not contain parasites. Flasks were sampled $(2.5 \mathrm{ml})$ weekly and the number of parasites, pyruvate and lactate were determined. Pyruvate and lactate were determined with test kits (Sigma Chemical Co., St. Louis, USA) and according to the manufacturers' instructions.

To determine pyruvate, $2.0 \mathrm{ml}$ of MEM with parasites from flasks in each group (A, B, or C) was pipetted into a centrifuge tube containing $4.0 \mathrm{ml}$ of cold $8 \%$ perchloric acid. The solution was vortexed for $30 \mathrm{~s}$ and then held at $4^{\circ} \mathrm{C}$ for 5 min to ensure complete protein precipitation. Tubes were centrifuged for $3 \mathrm{~min}$ at $10700 \times g$ to pellet proteins. The supernatant $(2.0 \mathrm{ml})$ was placed in a $1 \mathrm{~cm}$ lightpath cuvette and $0.5 \mathrm{ml}$ of 1.5 M Tris(hydroxymethyl)aminomethane (Tris) was added. The cuvettes were inverted 5 times to ensure proper mixing before adding $0.5 \mathrm{ml}\left(1.0 \mathrm{mg} \mathrm{ml}^{-1}\right.$ in Tris) of nicotinamide adenine dinucleotide (NADH), mixed by inversion again and the absorbance was read at $340 \mathrm{~nm}$ against water as the reference. Next $0.05 \mathrm{ml}$ of $1000 \mathrm{U} \mathrm{ml}^{-1}$ of lactate dehydrogenase was added and inverted 5 times to mix. The cuvette was left to stand at room temperature for $5 \mathrm{~min}$ and the absorbence read at $340 \mathrm{~nm}$. The absorbence was re-read after another $5 \mathrm{~min}$ and if the decrease was less than $0.001 \mathrm{~min}^{-1}$, the reaction was considered complete. Amount of pyruvate was determined by subtracting the initial absorbance from the final absorbance and multiplying by 0.723 (conversion factor provided by Sigma).

To determine lactate, $1.0 \mathrm{ml}$ of a solution (400 $\mathrm{U} \mathrm{l}^{-1}$ of lactate oxidase, $2400 \mathrm{U} \mathrm{l}^{-1}$ horseradish peroxidase and chromogen precursors in 0.2 M glycine buffer; Sigma, St. Louis) was pipetted into a $1 \mathrm{~cm}$ lightpath cuvette. A $10 \mu \mathrm{l}$ volume of MEM from each flask in each group (A, B or C) was added to the cuvette and allowed to stand for $10 \mathrm{~min}$. The absorbance was read at $540 \mathrm{~nm}$ 
against a blank containing no sample. The lactate concentration in the sample was expressed $\left(\mathrm{mg} \mathrm{dl}^{-1}\right)$ as the absorbance of the test sample divided by the absorbance of the standard and multiplied by 40 (conversion factor provided by Sigma).

Statistical analysis. A 1-way analysis of variance (ANOVA) was used to determine significant differences between control and experimental groups. When the distribution was not normal and the variances unequal, an ANOVA on ranks was used. When the results were significantly different a pairwise comparison was performed using a Student Newman-Keuls test (for parametric data) or a Dunn's test (for nonparametric data).

\section{RESULTS}

\section{Purification of microbodies in Cryptobia salmositica and detection of enzymes}

Differential and isopycnic centrifugation of Cryptobia salmositica lysates resulted in a suspension of organelles which contained catalase and equilibriated at a density of $1.21 \mathrm{~g} \mathrm{~cm}^{-3}$ (Fig. 1). Fig. $2 \mathrm{a}-\mathrm{g}$ shows the electrophoretic mobilities and patterns of catalase, triosephosphate isomerase, glyceraldehyde-phosphate dehydrogenase, glucosephosphate isomerase, hexokinase, lactate dehydrogenase and fructose-1,6-biphosphate aldolase. Lactate dehydrogenase was only detected in whole cell lysates while the remaining enzymes were detected in whole cell lysates and purified organelles. The 2 strains of C. salmositica did not differ from each other in staining and migration patterns of the 7 enzymes. In addition, the mobilities and staining patterns of enzymes in both whole cell lysates and purified organelles were similar (Fig. 2a-g).

\section{Catalase activity}

A microbody with a positive catalase reaction was present in thin sections of pathogenic and nonpathogenic Cryptobia salmositica. After incubation in 3,3'diaminobenzidine tetrahydrochloride, a weak electrondense reaction product was detected in microbodies. This reaction confirmed that the organelles were glycosomes. Glycosomes were found in C. salmositica (pathogenic and nonpathogenic strains) when parasites were isolated from the blood of fish (Fig. 3a). The reaction intensity increased in the glycosomes after parasites were cultured for more than 4 wk (Fig. 3b) and the reaction was inhibited by 3-amino-1,2,4-triazole (Fig. 3c). After 2.5 mo in culture, the pathogenic strain of C. salmositica (with strong reaction) was re-inocu-

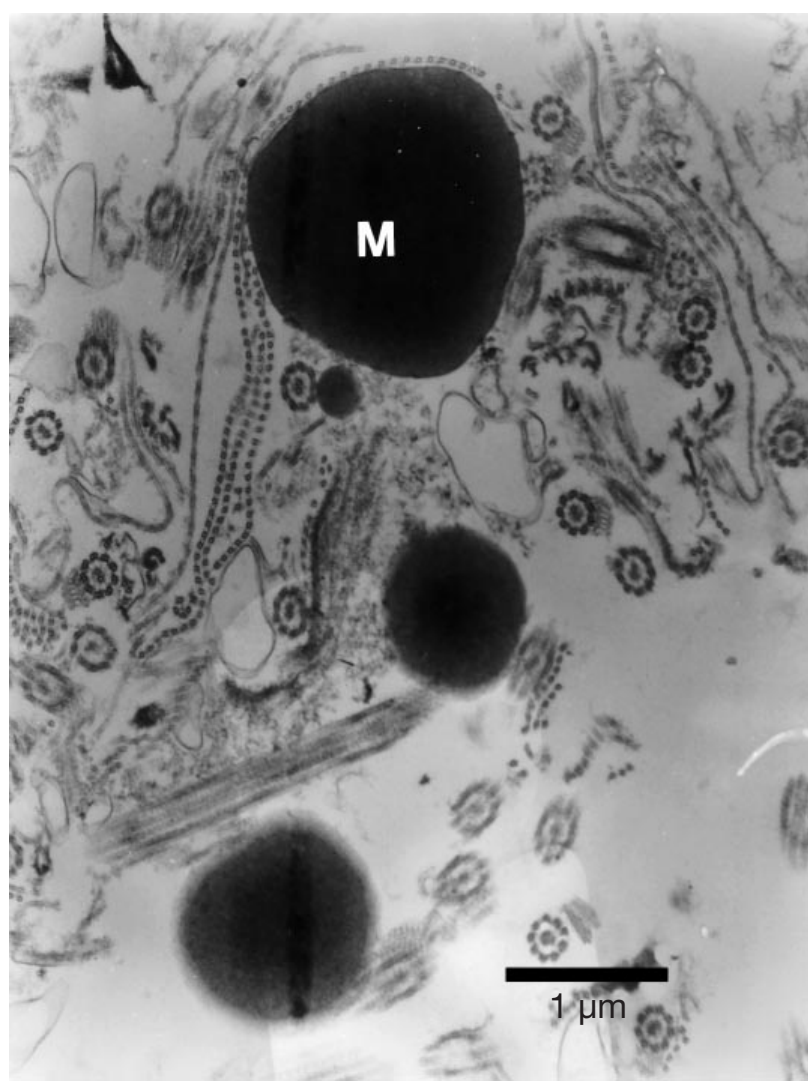

Fig. 1. Cryptobia salmositica. Electron micrograph of microbodies after differential and isopycnic centrifugation. M: microbody

lated into rainbow trout and the nonpathogenic strain (with strong reaction) was re-inoculated into chinook salmon. Both strains were re-isolated after $4 \mathrm{wk}$, and the reaction product was once again weak after incubation in 3, 3'-diaminobenzidine tetrahydrochloride.

Catalase activity was highest in homogenates of pathogenic Cryptobia salmositica after $8 \mathrm{wk}$ (21 nM $\mathrm{mg}^{-1}$ protein) in culture. When newly isolated from the blood of fish, catalase activity was low $\left(6 \mathrm{nM} \mathrm{mg}^{-1}\right.$ protein), but increased after $4 \mathrm{wk}$ (15 $\mathrm{nM} \mathrm{mg}{ }^{-1}$ protein). After 2.5 mo in culture, the pathogenic strain (with high catalase activity) was re-inoculated into rainbow trout. It was re-isolated after $4 \mathrm{wk}$, and catalase activity was once again weak ( $7 \mathrm{nM} \mathrm{mg}^{-1}$ protein). Catalase activity in homogenates of nonpathogenic C. salmositica increased over time under in vitro conditions. Activity was lowest at $4 \mathrm{wk}\left(29 \mathrm{nM} \mathrm{mg}^{-1}\right.$ protein) and highest at $8 \mathrm{wk}\left(55 \mathrm{nM} \mathrm{mg}^{-1}\right.$ protein).

\section{Characteristics of Cryptobia salmositica glycosomes}

Depending on the angle of the section, glycosomes were spherical to ovoid in shape and had a single lim- 

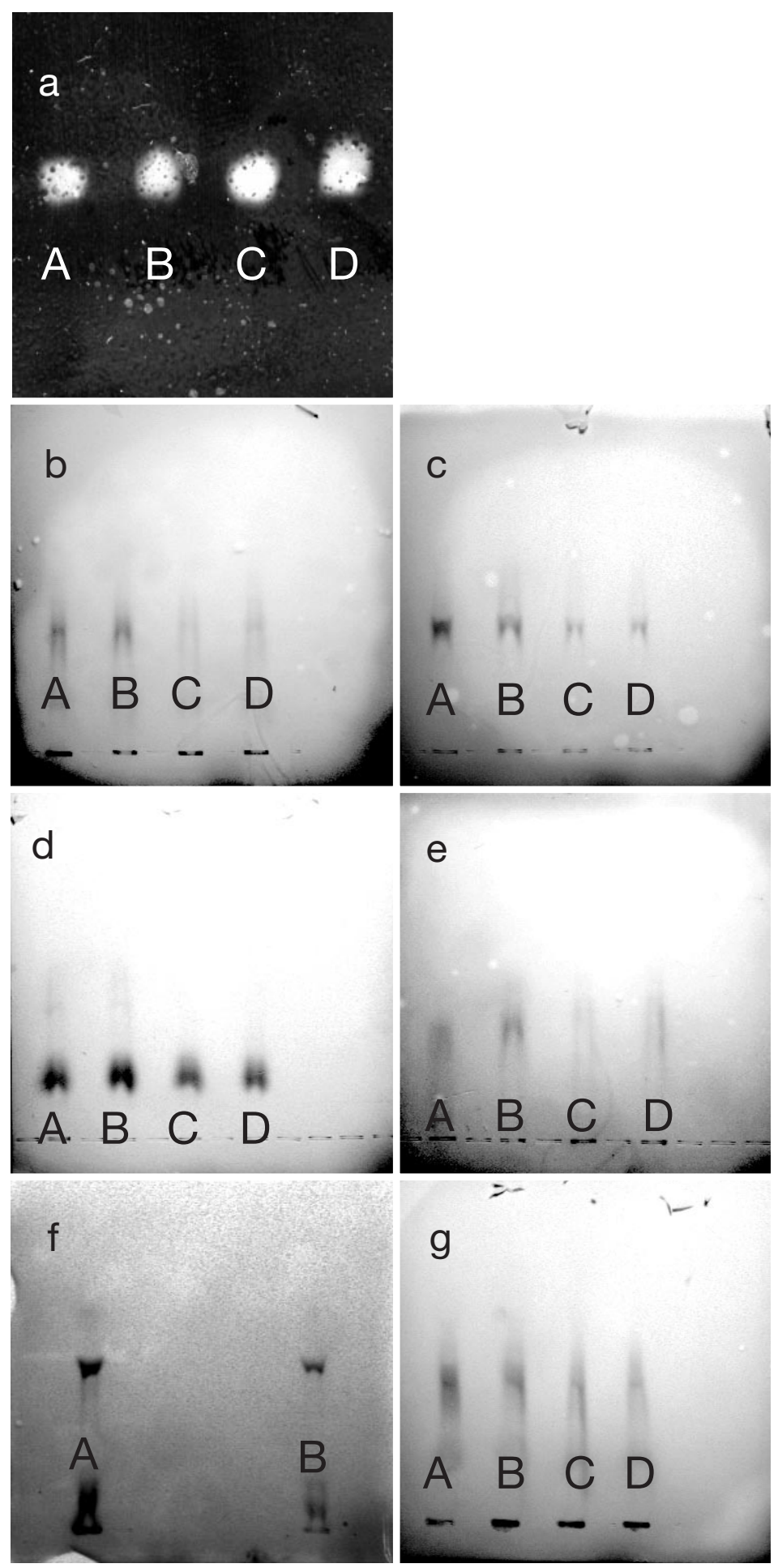

Fig. 2. Cryptobia salmositica. Mobilities and staining patterns of enzymes in pathogenic and nonpathogenic strains. Lane A: whole cell lysate of pathogenic strain; Lane B: purified organelles of pathogenic strain; Lane C: whole cell lysate of nonpathogenic strain; Lane D: purified organelles of nonpathogenic strain. (a) Catalase; (b) triosephosphate isomerase; (c) glyceraldehyde-3-phosphate dehydrogenase; (d) glucosephosphate isomerase; (e) hexokinase; (f) lactate dehydrogenase; (g) fructose-1, 6-biphosphate aldolase iting membrane (Fig. 3d). The matrix was granular and sometimes contained an electron-dense core (Fig. 4a). Both pathogenic and nonpathogenic strains had on average one microbody per section with a maximum of 8 microbodies in some sections.

These microbodies fused with vacuoles (Fig. 4b) and lipid droplets (Fig. 4c), and expelled their contents into the cytoplasm of the cell (Fig. 4d). At the site of fusion with lipid droplets or vacuoles, there was degradation of the microbody membrane and the microbody was typically darker and more granular during fusion (Fig. 4e).

Glycosomes increased in number by transverse division and budding. The first indication of division was an indentation of the membrane followed by the formation of a cleavage furrow (Fig. 5a). Division commonly produced 2 approximately equal sized organelles. Budding also occurred and up to 5 smaller microbodies were observed associated with a parent microbody (Fig. 5b).

\section{End products of carbohydrate metabolism}

Both pathogenic and nonpathogenic strains of Cryptobia salmositica produced lactate and pyruvate under in vitro conditions. The nonpathogenic strain multiplied faster than the pathogenic strain, and the numbers were significantly higher from 5 to 8 wk after inoculation into the culture medium (Fig. 6). Even though the pathogenic strain was present in lower numbers, it generally produced more lactate (Fig. 7) and pyruvate (Fig. 8) than the nonpathogenic strain. Exceptions occurred at $6 \mathrm{wk}(\mathrm{p}=0.0048)$ (for pyruvate) and $2 \mathrm{wk}(\mathrm{p}=0.0426)$ (for lactate) after inoculation in which the nonpathogenic strain produced more than the pathogenic strain. Generally, if lactate levels decreased the pyruvate levels increased in both strains. In both strains, more lactate was produced than pyruvate.

\section{DISCUSSION}

Carbohydrate metabolism in piscine haemoflagellates has not been well studied and nothing is known of their metabolism in their vectors. The present study demonstrated that some enzymes of the Embden-Meyerhof 

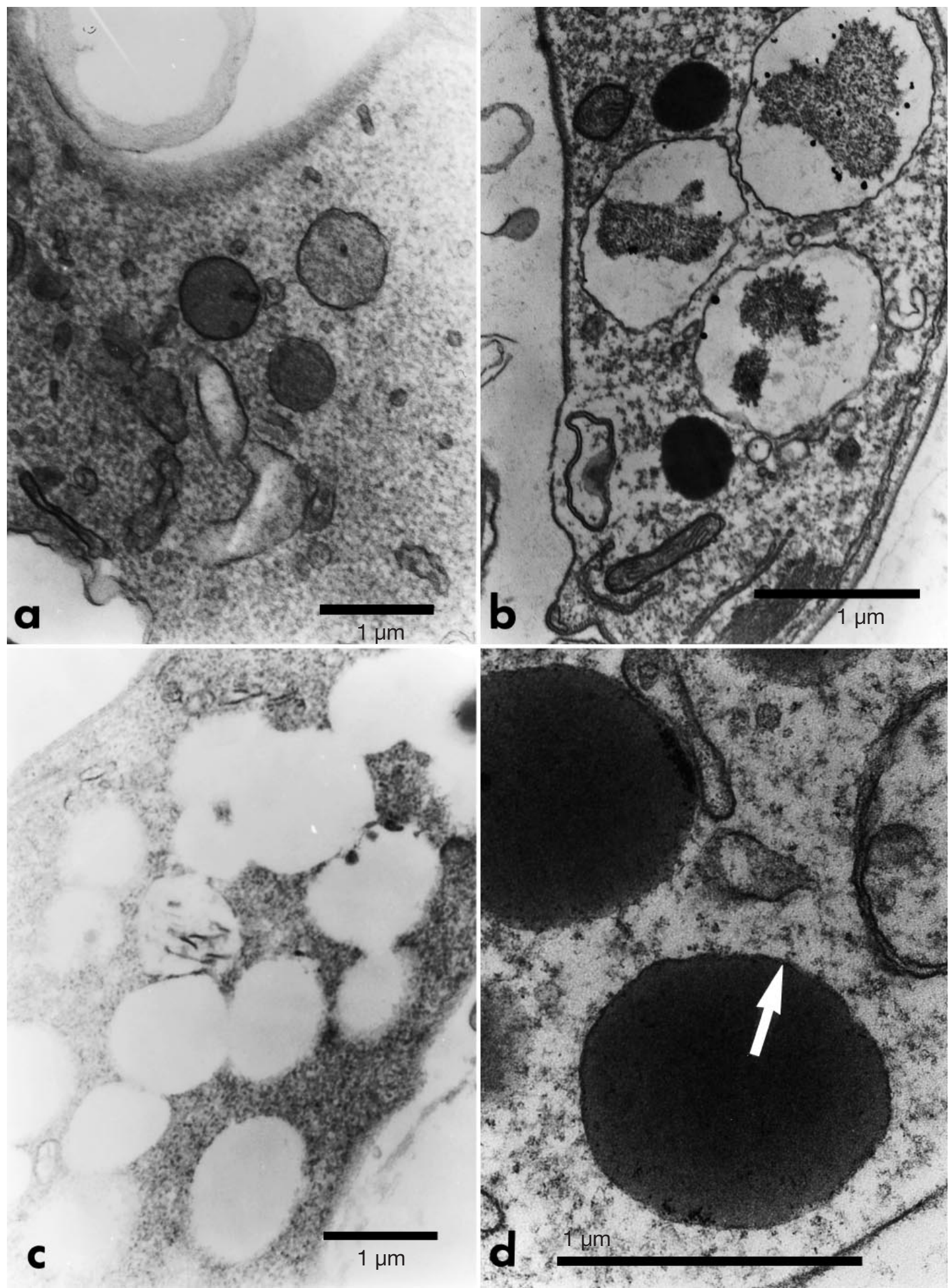

Fig. 3. (a) Cryptobia salmositica. Weak reaction product in glycosomes of pathogenic C. salmositica after incubation in 3, 3'diaminobenzidine tetrahydrochloride. (b) Strong reaction product in glycosomes of pathogenic C. salmositica after incubation in 3,3'-diaminobenzidine tetrahydrochloride. (c) Inhibition of 3,3'-diaminobenzidine tetrahydrochloride by aminotriazole. (d) Microbodies with a single limiting membrane (arrow) 

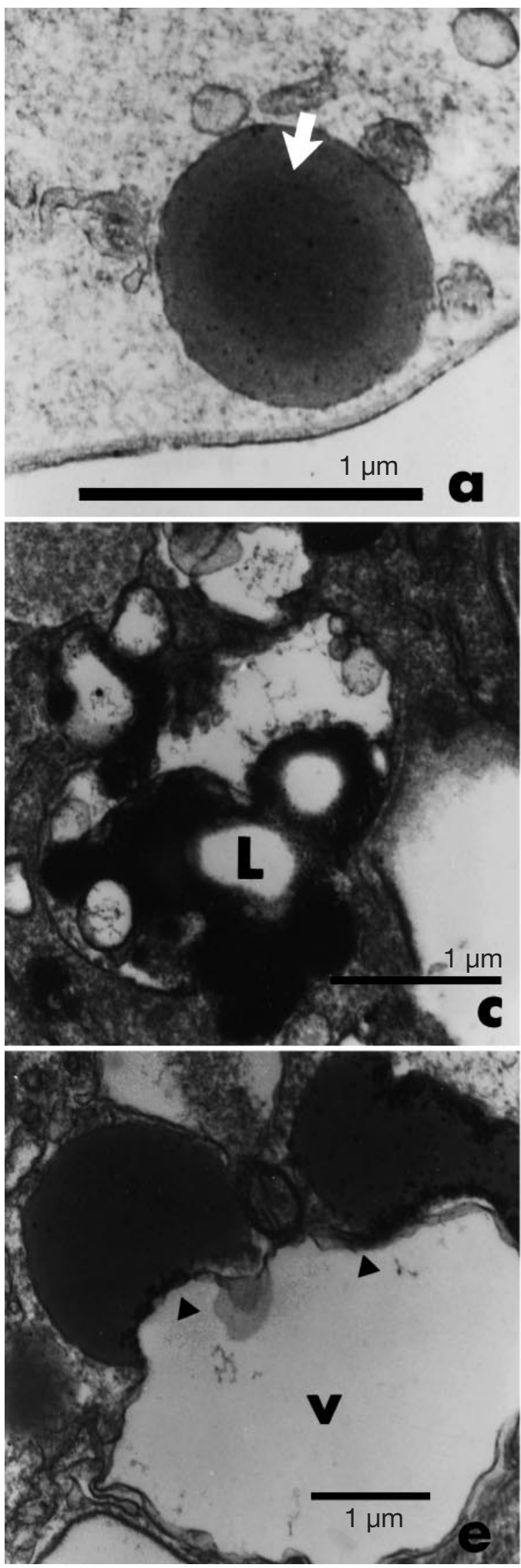

pathway in Cryptobia salmositica (pathogenic and nonpathogenic strains) were located in a subcellular microbody, the glycosome. This is similar to other Kinetoplastida (Opperdoes 1995).

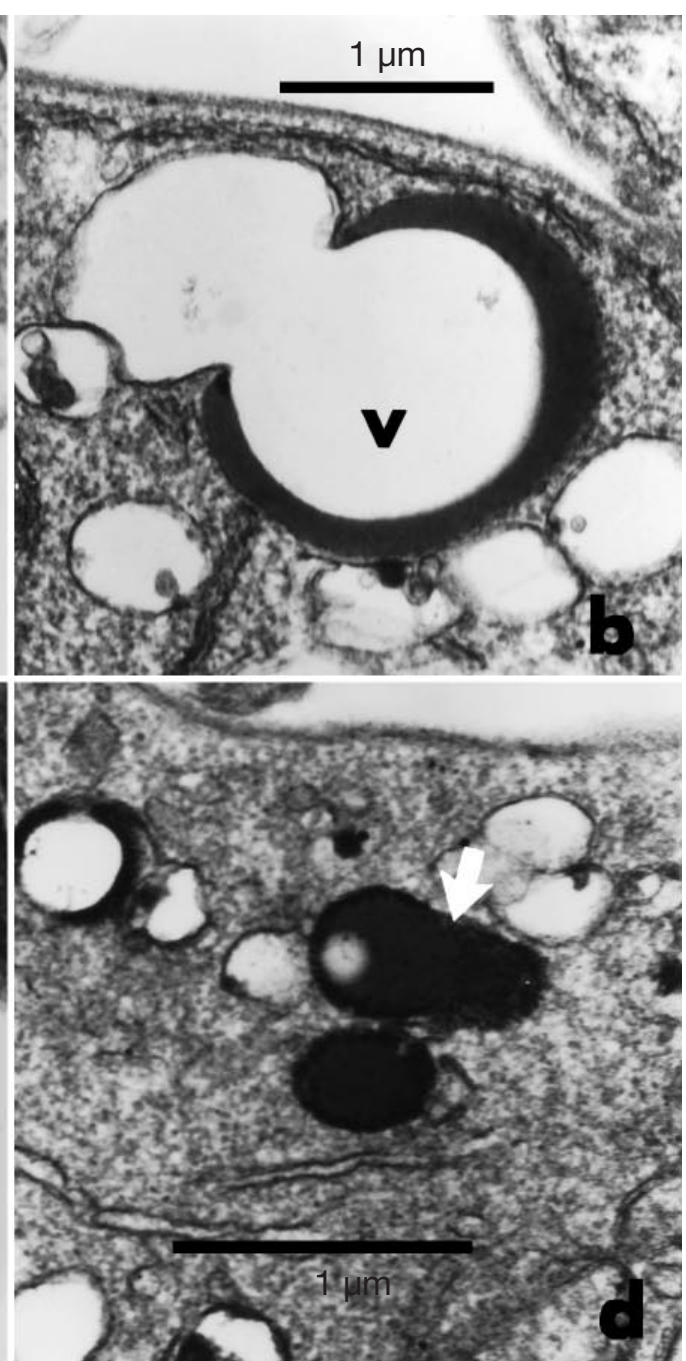

Fig. 4. Cryptobia salmositica. (a) Glycosome with a core (arrow). (b) Glycosome fusing with vacuole (v). (c) Glycosome fusing with lipid droplet (L). (d) Glycosome expelling contents into the cytoplasm. Arrow: catalase. (e) Degradation of the microbody membrane when fusing with a vacuole. v: vaculole; arrowheads: sites of fusion showing granular appearance of the membrane

The glycosome belongs to a family of microbodies which includes peroxisomes (in eukaryotes) and glyoxysomes (in germinating plants). There is evidence that glycosomes and peroxisomes have a shared 

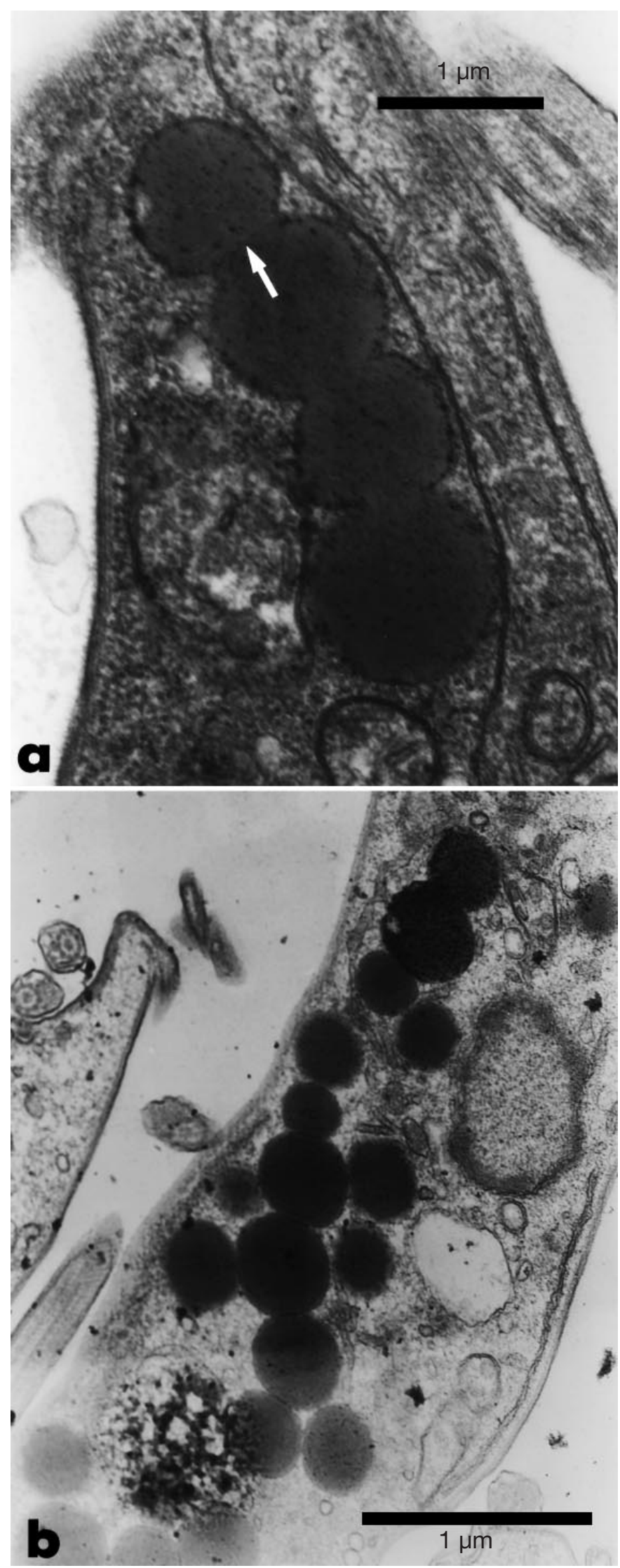

Fig. 5. Cryptobia salmositica. (a) Dividing glycosomes. Arrow: cleavage furrow. (b) Chain of diving glycosomes

ancestry as they have several common enzymes and pathways. Both microbodies contain catalase and enzymes involved in fatty acid metabolism and biosynthesis of ether lipids. Similar to peroxisomes, glycosomal proteins are synthesized on free ribosomes and then transported post-translationally into the organelle without removal of a cleavable leader sequence. Morphological similarities include an electron-dense granular matrix, a crystalloid core and a single limiting membrane. Furthermore glycosomes have a banding density in sucrose which is similar to peroxisomes (Opperdoes 1995). The present study demonstrated that glycosomes, similarly to peroxisomes, fused with lipid bodies and vacuoles, divided from pre-existing glycosomes, expelled their contents into the cytoplasm and could modify the amount of catalase.

Catalase is a marker enzyme for peroxisomes and is present in aerobic animal and plant cells containing a cytochrome system. The main function of catalase is to split hydrogen peroxide into water and oxygen and to oxidize hydrogen

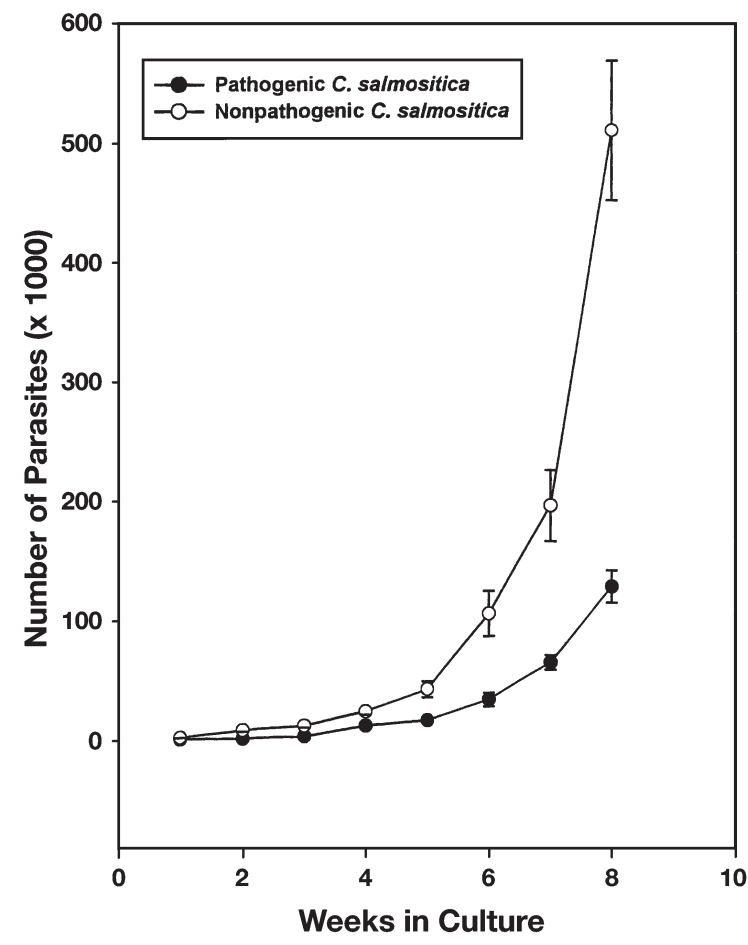

Fig. 6. Cryptobia salmositica. Multiplication in Minimum Essential Medium 


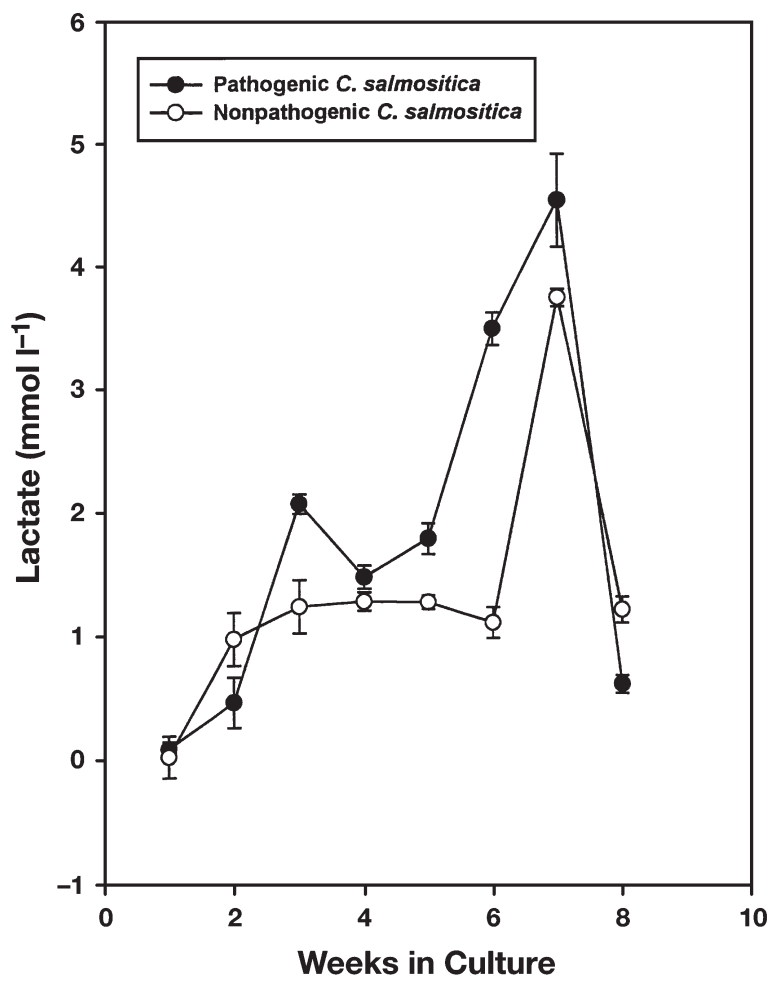

Fig. 7. Cryptobia salmositica. Lactate production under in vitro conditions

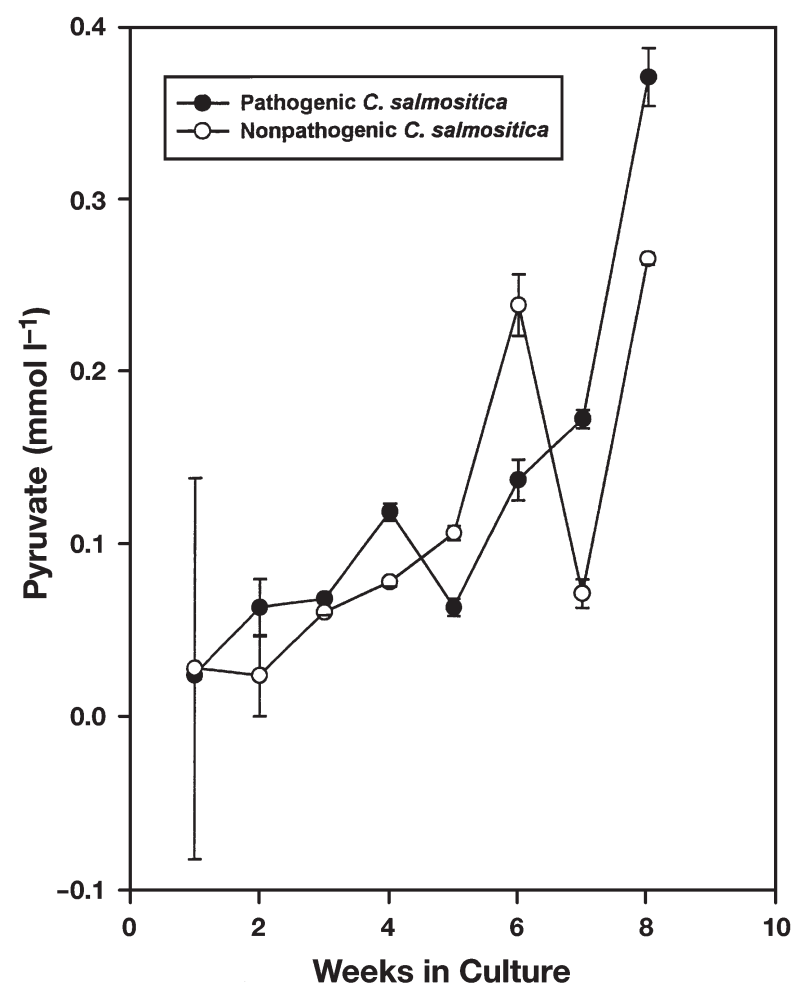

Fig. 8. Cryptobia salmositica. Pyruvate production under in vitro conditions donors. The peroxidatic activity of catalase on diaminobenzidine tetrahydrochloride forms the basis for the cytochemical detection of the enzyme. However the diaminobenzidine reaction is nonspecific and can also be used to identify peroxidase and cytochrome $C$ oxidase. This non-specificity can be a problem because catalase, peroxidase and cytochrome $c$ oxidase may occur together within the same organelle (Diemann et al. 1991). To unequivocally identify a catalase, a specific inhibitor such as aminotriazole, dichlorophenol, potassium cyanide or sodium azide (Fahimi 1969) should be used. The activity of catalase in glycosomes of the Kinetoplastida is variable and has been detected in several parasites including Phytomonas spp. of plants (Sanchez-Moreno et al. 1992), Cryptobia (= Trypanoplasma) borreli of cyprinids (Opperdoes et al. 1988), Crithidia spp. of insects (Muse \& Roberts 1973) and Leptomonas samueli of reptiles (Souto Padron \& De Souza 1982).

An electron-dense reaction product was detected in microbodies of cultured Cryptobia salmositica (pathogenic and nonpathogenic strains) after incubation with diaminobenzidine tetrahydrochloride. The reaction product was inhibited by aminotriazole, demonstrating that the product in the microbody was catalase. The catalase activity was weak when parasites were newly isolated from the blood of fish, and increased with time in culture. This was confirmed when catalase activity was measured enzymatically. This indicates that $C$. salmositica can modify the amount of catalase in its microbody in response to the environment. We suggest that the increase in catalase was a response to accumulation of oxidative metabolites in culture, and that they included hydrogen peroxide which the parasites excreted into the media (unpubl. obs.). The parasite requires an efficient antioxidant such as catalase to detoxify the hydrogen peroxide. The catalase activities were weak when parasites were in the blood of fish as it was unlikely the end products of parasite metabolism would accumulate in the host.

Catalase activity and the activity of 5 glycolytic enzymes were associated with a microbody that had a buoyant density of $1.21 \mathrm{~g} \mathrm{~cm}^{-3}$ in sucrose. Thin sections of Cryptobia salmositica indicated a catalase-containing microbody which was morphologically similar to the isolated microbody (density $1.21 \mathrm{~g} \mathrm{~cm}^{-3}$ ). This confirms that C. salmositica microbodies contain catalase as well as glycolytic enzymes and are thus glycosomes.

The electrophoretic patterns of enzymes are often used to distinguish parasite isolates (Sargeaunt \& Williams 1978, Kollaritsch et al. 1989, Vargas \& Orozco 1993) and to study zymodeme alterations under varying conditions (Clark et al. 1992, Mukherjee et al. 1993). Our study demonstrated that the migration and staining patterns of several glycolytic enzymes were 
similar in the pathogenic and nonpathogenic strains of Cryptobia salmositica. A pathogenic strain of Entamoeba histolytica was also attenuated by serial passage (Mirelman et al. 1986) and there was a gradual change in the virulent properties of the trophozoites. This was accompanied by a shift in the isoenzyme pattern for hexokinase and phosphoglucomutase as well as a distinct change in morphology. This is similar in $C$. salmositica as the nonpathogenic strain in culture is smaller than the pathogenic strain. Also the nonpathogenic strain has fewer polypeptides and some of the bands are antigenically distinct (Woo \& Thomas 1991). Pathogenic and nonpathogenic isolates of parasites are known to differ in their isozyme patterns, particularly their hexokinase (Mirelman et al. 1986) and although our study did not reveal differences between the 2 strains, an analysis of other enzymes may be rewarding.

Cryptobia salmositica is aerobic (Thomas et al. 1992), uses glucose and L-glutamine, and utilization of glucose increases with parasite multiplication (Li \& Woo 1991). Similarly, other Kinetoplastida can catabolize a variety of carbohydrates such as glucose, fructose, mannose and glycerol (Opperdoes 1995). Under aerobic conditions the long slender bloodstream Trypanosoma brucei metabolize glucose to pyruvate, which is the sole end product of glycolysis. Pyruvate is not converted into lactate because the organism lacks lactate dehydrogenase (Fairlamb \& Opperdoes 1986). Transformation of the trypanosome bloodstream form into the procyclic insect stage is accompanied by changes in glucose metabolism and end products (Tielens \& Van Hellemond 1998). For example, pyruvate is no longer excreted but is metabolized further inside the mitochondria. It is first decarboxylated to acetyl-CoA and some of it is then degraded to carbon dioxide via the Krebs cycle. Much of the acetyl-CoA does not enter the Krebs cycle, but is converted to acetate. C. salmositica (pathogenic and nonpathogenic strains) produced both pyruvate and lactate; when pyruvate was low, lactate increased. We suggest that the pyruvate was converted to lactate because, in contrast to $T$. brucei, these parasites have lactate dehydrogenase. Similar to the majority of the Kinetoplastida, C. salmositica produced L-lactate, in contrast to Leishmania spp. which are the only trypanosomatids known to produce D-lactate (Opperdoes 1995). In the present study there was a significant decline in lactate at $8 \mathrm{wk}$ after culture. This was unexpected and if pyruvate was converted into lactate, then concentrations were expected to increase. The decline in lactate and pyruvate might be because oxygen was depleted from the media; after $8 \mathrm{wk}$ in culture, there is a significant decline in oxygen concentration in culture media of C. salmositica (unpubl. obs.). In $T$. brucei transformation from aerobiosis to anaerobiosis is characterized by a decrease in levels of all metabolites as well as ATP (Visser \& Opperdoes 1980). Carbon balance studies were not performed in the present study, and thus it cannot be concluded that pyruvate and lactate are the sole end products of glycolysis. Further studies should examine the production of glycerol, acetate, ethanol, and alanine in these parasites.

Cryptobia salmositica (pathogenic and nonpathogenic strains) have the first 5 enzymes of the EmbdenMeyerhoff pathway, and the peroxisomal enzyme catalase sequestered within the glycosome. Pyruvate and lactate were produced as a result of glucose metabolism. The glycosome in C. salmositica may provide an advantage to the parasite in allowing it to switch between glycosomal glycolysis and mitochondrial respiration. This switch may occur in the leech vector (hypoxic conditions) or after exposure to some chemotherapeutic agents which damage the mitochondria (Ardelli \& Woo 1998).

Acknowledgements. This study was supported by grants from the National Sciences and Engineering Research Council (NSERC) of Canada to P.T.K.W.

\section{LITERATURE CITED}

Archer RK (1965) Haematological techniques for use on animals. Blackwell Scientific Publications, Oxford

Ardelli BF, Woo PTK (1998) The in vitro effects of crystal violet on the pathogenic piscine haemoflagellate Cryptobia salmositica Katz, 1951 (Sarcomastigophora: Kinetoplastida). Parasite 5:27-36

Ardelli BF, Forward GM, Woo PTK (1994) Brook charr, Salvelinus fontinalis, and cryptobiosis: a potential salmonid reservoir host for Cryptobia salmositica Katz, 1951. J Fish Dis 17:567-577

Becker CD, Katz M (1965) Transmission of the haemoflagellate Cryptobia salmositica Katz 1951, by a rhynchobdellid leech vector. J Parasitol 51:95-99

Bower SM, Margolis L (1984) Detection of infection and susceptibility of different Pacific salmon stocks (Oncorhynchus spp.) to the haemoflagellate Cryptobia salmositica. J Parasitol 70:273-278

Bradford MW (1976) A rapid and sensitive method for the quantitation of microgram quantities of protein utilizing the principle of protein-dye binding. Anal Biochem 72:248-254

Clark CG, Cunnick CC, Diamond LS (1992) Entamoeba histolytica: is conversion of 'nonpathogenic' amebae to the 'pathogenic' form a real phenomenon? Exp Parasitol 74: 307-314

Diemann W, Angermüller S, Stoward PJ, Fahimi HD (1991) Peroxidases. Histochemistry, theoretical and applied. Churchill Livingstone, Edinburgh

Fahimi HD (1969) Cytochemical localization of peroxidatic activity of catalase in rat hepatic microbodies (peroxisomes). J Cell Biol 43:275-286

Fairlamb AH, Opperdoes FR (1986) Carbohydrate metabolism in African trypanosomes, with special reference to the glycosome. In: Morgan MJ (ed) Carbohydrate metabolism of cultured cells. Plenum Press, New York, p 183-224 
Harris H, Hopkinson DA (1976) Handbook of enzyme electrophoresis in human genetics. North-Holland, Amsterdam

Hebert PDN, Beaton MJ (1993) Methodologies for allozyme analysis using cellulose acetate electrophoresis. A practical handbook. Helena Laboratories, Beaumont

Kollaritsch H, Graf J, Stemberger H, Krumpolz B, Binder M, Scheiner O, Weidermann G (1989) Interaction of different strains of Entamoeba histolytica with target cells: characterization of electrophysiological and morphological features. Immunobiol 179:190-201

Li S, Woo PTK (1991) In vitro effects of fetal bovine serum and glucose on multiplication of Cryptobia salmositica. J Parasitol 77:151-155

Li S, Woo PTK (1995) Efficacy of a live Cryptobia salmositica vaccine, and the mechanism of protection in vaccinated rainbow trout, Oncorhynchus mykiss, against cryptobiosis. Vet Immunol Immunopathol 48:343-353

Lück H (1963) Catalase. In: Bergmeyer HU (ed) Methods of enzymatic analysis. Academic Press, New York, p 885

Mirelman D, Bracha R, Chayen A (1986) Entamoeba histolytica: effect of growth conditions and bacterial associates on isoenzyme patterns and virulence. Exp Parasitol 62: $142-148$

Mukherjee RM, Bhol KC, Mehra S, Maitra TK, Jalan KN (1993) Zymodeme alteration of Entamoeba histolytica isolates under varying conditions. Trans R Soc Trop Med Hyg 84:490-491

Muse KE, Roberts JF (1973) Microbodies in Crithidia fasciculata. Protoplasma 78:343-348

Opperdoes FR (1988) Glycosomes may provide clues to the import of peroxisomal proteins. Trends Biochem Sci 13: $255-260$

Opperdoes FR (1995) Carbohydrate and energy metabolism in aerobic protozoa. In: Marr JJ, Müller M (eds) Biochemistry and molecular biology of parasites. Academic Press, London, p 19-32

Opperdoes FR, Borst P (1977) Localization of nine glycolytic enzymes in a microbody-like organelle in Trypanosoma brucei: the glycosome. FEBS Lett 80:360-364

Opperdoes FR, Baudhuin P, Coppens I, de Roe C, Edwards SW, Weijers PJ, Misset O (1984) Purification, morphometric analysis, and characterization of the glycosomes (microbodies) of the protozoan haemoflagellate Trypanosoma brucei. J Cell Biol 98:1178-1184

Opperdoes FR, Nohynkova E, Van Schaftingen E, Lambier AM, Veenhuis M, Van Roy J (1988) Demonstration of glycosomes (microbodies) in the Bodonid flagellate Trypanoplasma borreli (Protozoa, Kinetoplastida). Mol Biol Parasitol 30:155-164

Price CA (1982) Centrifugation in density gradients. Academic Press, New York

Sanchez-Moreno M, Lasztity D, Coppens I, Opperdoes FR (1992) Characterization of carbohydrate metabolism and demonstration of glycosomes in a Phytomonas sp. isolated from Euphorbia characias. Mol Biol Parasitol 54:185-200

Editorial responsibility: Wolfgang Körting,

Hannover, Germany
Sargeaunt PG, Williams JE (1978) Electrophoretic isoenzyme patterns of Entamoeba histolytica and Entamoeba coli. Trans R Soc Trop Med Hyg 72:164-166

Shaw CR, Prasad R (1970) Starch gel electrophoresis of enzymes - a compilation of recipes. Biochem Genet 4: $297-320$

Sitja-Bobadilla A, Woo PTK (1994) An enzyme-linked immunosorbent assay (ELISA) for the detection of antibodies against the pathogenic haemoflagellate, Cryptobia salmositica Katz, and protection against cryptobiosis in juvenile rainbow trout, Oncorhynchus mykiss (Walbaum) inoculated with a live vaccine. J Fish Dis 17:399-408

Souto Padron T, De Souza W (1982) Fine structure and cytochemistry of peroxisomes (microbodies) in Leptomomas samueli. Cell Tissue Res 222:153-158

Thomas PT, Ballantyne JS, Woo PTK (1992) In vitro oxygen consumption and motility of Cryptobia salmositica, Cryptobia bullocki, and Cryptobia catostomi (Sarcomastigophora: Kinetoplastida). J Parasitol 78:747-749

Tielens AGM, Van Hellemond JJ (1998) Differences in energy metabolism between trypanosomatidae. Parasitol Today 14:265-271

Vargas MA, Orozco E (1993) Entamoeba histolytica: changes in the zymodeme of cloned nonpathogenic trophozoites cultured under different conditions. Parasitol Res 79: $353-356$

Visser N, Opperodes FR (1980) Glycolysis in Trypanosoma brucei. Eur J Biochem 103:623-632

Woo PTK (1979) Trypanoplasma salmositica, experimental infections in rainbow trout Salmo gairdneri. Exp Parasitol 47:36-48

Woo PTK, Li S (1990) In vitro attenuation of Cryptobia salmositica and its use as a live vaccine against cryptobiosis in Oncorhynchus mykiss. J Parasitol 76:752-755

Woo PTK, Poynton SL (1995) Diplomonadida, Kinetoplastida and Amoebida (Phylum Sarcomastigophora. In: Woo PTK (ed) Fish diseases and disorders I. Protozoan and metazoan infections. CAB International, Wallingford, p 27-96

Woo PTK, Thomas PT (1991) Polypeptide and antigen profiles of Cryptobia salmositica, C. bullocki and C. catostomi (Kinetoplastida: Sarcomastigophora) isolated from fishes. Dis Aquat Org 11:201- 205

Woo PTK, Thomas PT (1992) Comparative in vitro studies on virulent and avirulent strains of Cryptobia salmositica Katz, 1951 (Sarcomastigophora: Kinetoplastida). J Fish Dis 15:261-266

Woo PTK, Wehnert SD (1983) Direct transmission of a haemoflagellate, Cryptobia salmositica (Kinetoplastida: Bodonina) between rainbow trout under laboratory conditions. J Protozool 30:334-337

Zuo X, Woo PTK (1996) Acid phosphatase in the pathogenic and nonpathogenic haemoflagellates, Cryptobia spp., of fishes. J Parasitol 82:893-899

Zuo X, Woo PTK (1997) Proteases in pathogenic and nonpathogenic haemoflagellates, Cryptobia spp. (Sarcomastigophora: Kinetoplastida) of fishes. Dis Aquat Org 29:57-65

Submitted: January 18, 2000; Accepted: March 30, 2000

Proofs received from author(s): July 20, 2000 